\title{
MBE Growth of GaInAsSb p/n. Junction Diodes for Thermophotovoltaic Applications
}

$$
\text { CONF-960834-- }
$$

G. W. Charache, P. Uppal, et. al.

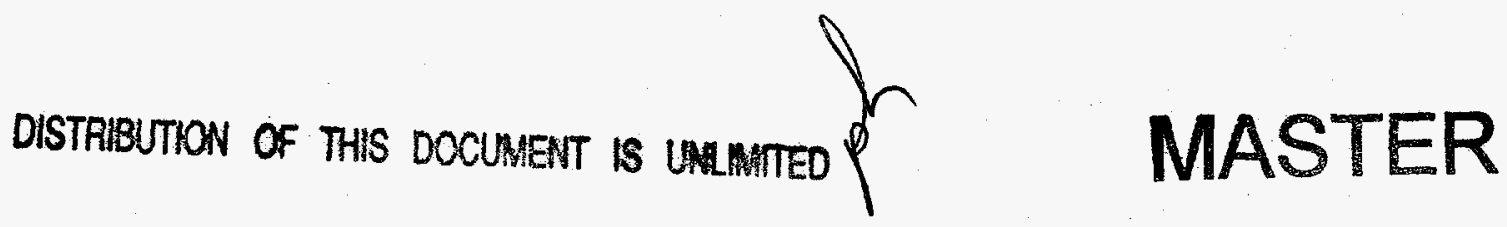

\section{NOTICE}

This report was prepared as an account of work sponsored by the United States Government. Neither the United States, nor the United States Department of Energy, nor any of their employees, nor any of their contractors, subcontractors, or their employees, makes any warranty, express or implied, or assumes any legal liability or responsibility for the accuracy, completeness or usefulness of any information, apparatus, product or process disclosed, or represents that its use would not infringe privately owned rights.

Operated for the U. S. Department of Energy by KAPL, Inc. a Lockheed Martin company 


\section{DISCLAIMER}

This report was prepared as an account of work sponsored by an agency of the United States Government. Neither the United States Government nor any agency thereof, nor any of their employees, make any warranty, express or implied, or assumes any legal liability or responsibility for the accuracy, completeness, or usefulness of any information, apparatus, product, or process disclosed, or represents that its use would not infringe privately owned rights. Reference herein to any specific commercial product, process, or service by trade name, trademark, manufacturer, or otherwise does not necessarily constitute or imply its endorsement, recommendation, or favoring by the United States Government or any agency thereof. The views and opinions of authors expressed herein do not necessarily state or reflect those of the United States Government or any agency thereof. 


\section{DISCLAIMER}

Portions of this document may be illegible in electronic image products. Images are produced from the best available original document. 


\title{
MBE Growth of GaInAsSb p/n Junction Diodes for Thermophotovuitaic
} Applications

by

\author{
Parvez N. Uppal"
}

Phone: (603)885-1016, Fax: (603)885-1074

Sanders, A Lockheed Martin Company, NHQ6-1551, G5 Spit Brook Road, Nashua NH, 03061

Greg Charache, Paul Baldasaro and Brian Campbell

Lockheed Martin, P.O. Box 1072, Schenectady, NY 12301

Stephen Loughin

Lockheed Martin Astro Space, P.O. Box 8555, Philadelphia, PA 19101

Stefan Svensson

ARL, AMSRL-PS-PB, 2800 Powder Mill Rd., Adelphi, MD 20783

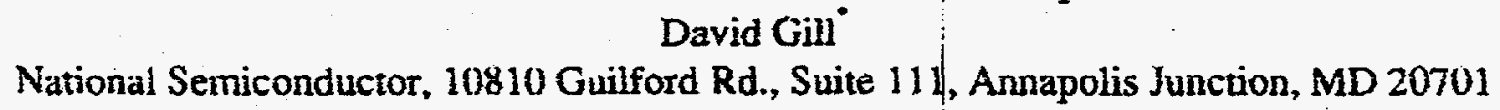

Abstract

This paper reports recent progress in the development of quaternary III-V thermophotovoltaic (TPY) devices based on MBE growh $\mathrm{Ga}_{2} \mathrm{In}_{1 . x} \mathrm{As}_{4} \mathrm{Sb}_{1-4} \mathrm{TPV}$ is of great interest for a variety of applications ${ }^{(12)}$. The objective of this work is to develop a TPV cell which is "tunable" to the emission spectrum of a heated blackbody, at temperatures in the range of $1200-1473 \mathrm{~K}$. One aspect of this "tuning" is to match the band gap, $\mathrm{E}_{\mathrm{sag}}$ " of the photovoltaic device to the peak output of the heat source. An advantage of the quaternary III-V semiconductor systems is that devices can be fabricated by molecular beam epitaxy on a suitable binary substrate, such as GaSb or InAs, and the band gap and lattice constant can be adjusted more or less independently, to match requirements. Quaternary cells, with band-gaps in the 0.5 to $0.72 \mathrm{eV}$ range, have been fabricated and tested. For $0.54 \mathrm{eV}$ devices we obtained $\mathrm{V}_{\mathrm{cx}}=0.3 \mathrm{~V}$ and $\mathrm{I}_{\mathrm{sc}}=1.5 \mathrm{amperes} / \mathrm{cm}^{2}$ under infrared illumination of a $1200 \mathrm{~K}$ blackbody. Under high illumination levels the $V_{c x}$ and $I_{s c}$ ranged from $0.5 \mathrm{~V}$ at 3 amperes $/ \mathrm{cm}^{2}$ for $0.72 \mathrm{eV}$ devices to $0.31 \mathrm{~V}$ at 1.2 amperes $/ \mathrm{cm}^{2}$ for $0.5 \mathrm{eV}$ devices, indicating good photovoltaic device characteristics over the range of bandgaps. The diode ideality factor for $0.54 \mathrm{eV}$ deyices ranged from 2.45 at low illumination indicating mnneling-dominated dark current, to 1.7 at high illumination intensity indicating recombination-generation dominated dark currents.

\section{Intruduction}

The elements of a TPV system include an emitter which is a heat source coupled to a blackbody radiator, a spectral control element (band-pass filter) and a photovoltaic converter which is matched to the blackbody and spectral control element. A schematic for a TPV system is shown in Figure 1.

Figure 2 compares the power emitted by a blackbody at various temperatures and compares the power at wavelengths shorter than the cut-off wavelengths for $\mathrm{GaSb}$, and two lower bandgaps. The three lower curves represent the maximum power available for conversion by cells with those bandgaps without taking into consideration any factors limiting their conversion efficiency. It must be pointed out that a high efficiency PV diode is only one aspect of demonstrating an efficient TPV system, an effective spectral

\footnotetext{
"Work done at Lockheed Marin Laboratories, Baitimors, MD 21227
} 
control device is critical to obtain high overall system efficiency. As an example, for a $1200 \mathrm{~K}$ blackbody, almost $70 \%$ of the blackbody power density lies below the bandgap of a $0.5 \mathrm{eV}$ bandgap $P V$ cell. This requires an efficient band-pass filter which reflects most of the radiation below the semiconductor bandgap out to $10-\mu \mathrm{m}$ back to the blackbody to recycle the photons and allows maximum transmittance above the semiconductor bandgap for the PV cell to conver.

Among the unique advantages of the quaternary GaInAsSb system are that the bandgap and the lattice constant can be adjusted to match the requirements. Figure 3 shows the alloy composition and the bandgap range of interest lattice matched to GaSb.

In this paper we present recent progress on obtaining large area (Icm $\times 1 \mathrm{~cm}$ ) variable bandgap GaInAsSb PV cell lattice matched to GaSb substrates with bandgaps between $0.72 \mathrm{eV}$ and $0.5 \mathrm{eV}$.

\section{Material Growth}

The material used for the fabrication of the GaInAsSb TPV devices was grown using a Varian Gen II MBE system. 2" n-type (1-2e17 $\left.\mathrm{cm}^{.3}\right)$ exact (001) oriented GaSb substrates were used. The oxide on these wafers was desorbed in-situ in the MBE system. The wafers were heated to about $400 \mathrm{C}$, then the $\mathrm{Sb}_{4}$ shutter was opened, the oxide was observed to come off at temperatures in the 525-535 $\mathrm{C}$ range as manitored by the pyrometer. An $\mathrm{n}+\left(\sim 5 \mathrm{e} 18 \mathrm{~cm}^{-3}\right) 100 \mathrm{~nm}$ GaSb buffer layer was grown to smooth the surface and improve the RHEED pattern. During the GaSb growth the substrate temperature was dropped to $500 \mathrm{C}$ and growth of GaInAsSb was initiated. This formed the base region of the TPV device and had a thickness of 5- $\mu \mathrm{m}$ and an n-type doping density of $2 \mathrm{e} 17 \mathrm{~cm}^{-1}$. Next the p-type emitter and p-type GaSb (300A) window layer were grown with a doping density of $1-2 \mathrm{e} 18 \mathrm{~cm}^{-3}$. Figure 4 shows a typical device structure.

In order to obtain the correct bandgap, $\mathrm{Ga}$ and In ratios were adjusted. To obtain the lattice constant match with the substrate, $A s$ and $S b$ ratios were adjusted. The GaInAsSb devices were lattice matched to within $0.05 \%$ with the substrate. When the mismatch exceeded $0.1 \%$ the wafer was observed to bend. The wafers bent in a convex shape with a plus (larger than the substrate-excess Sb) mismatch. The waters were observed to bend in a concave shape with a negative (smaller than the substrate-excess As) mismatch. This bending of wafers was much worse in the case of InAs substrates, because InAs is a softer material than GaSb. To relieve the lattice mismatch strain quaternary GalnAsSb appears to deform the layer instead of relieving strain by the formation of dislocations. This is presumably due to the alloy hardening effect of the second group $\mathrm{V}$ in the films. Due to this alloy hardening effect the layer finds it energetically difficult to produce and propagate dislocations and hence bends to relieve the strain. This bending of the wafers took place at the growth temperature and could be observed through the view port, this rules out the bending due to any co-efficient of thermal expansion mismatch. To further investigate the possibility of lattice mismatch related bending peculiar to the GalnSb material system we grew the ternary GalnSb (with the same $\mathrm{Ga}$ and In ratio as in the quatemary) on $\mathrm{GaSb}$, we did not observe any bending despite a much larger mismatch $(>0.5 \%)$. This indicates that in the mixed arsenide-antimonide quatemaries strain relaxation proceeds differently as compared to the ternaries, and can have important device implications. Further investigations using TEM are needed on the GalnAsSb quaternary system. 


\section{Device Fabrication and Characterization}

$1 \mathrm{~cm} \times 1 \mathrm{~cm}$ mesa diodes were fabricated using dhemical etching, the mesa diodes had a single $1 \mathrm{~mm}$ wide central busbar for making electrical contact to the devices. The busbar was connected to grid lines $0.5 \mathrm{~cm}$ long $100-\mu \mathrm{m}$ apart and $10-\mu \mathrm{m}$ wide. Front metallization was done by evaporating $\mathrm{Ti}$ and $\mathrm{Pt}$ in an e-beam evaporator and then depositing i 5-Hm thick Au or Al to obtain a low resistance contact for high current densities. For bottom Ohmic contact a thick Sn/Pt or Sin/Au was used. A 0.2- $\mu \mathrm{m}$ Silicon Nitride layer on top was used as an antireflection coating.

The diodes were tested under dark and under blackbody illuminated conditions. Figure 5 shows an external quantum efficiency vs wavelength for a typical device. The Figure shows a comparison for a typical $\mathrm{GaSb}$ and $\mathrm{GaIn} A \mathrm{sSb}$ device. The fall off at short wavelengths indicates high surface recombination, pointing to the need for an effective front surface passivation or a high bandgap window layer. A softer roll off in quantum efficiency at wavelengths near the band edge indicates the absence of an effective back surface field. Adding these two layers to the devices will considerably improve their performance.

Figure 6 shows comparison of a typical I-V characteristics from a GalnAsSb and GaSb PV diodes under similar low light level illumination conditions. As is to be expected the short circuit current is higher for the lower bandgap device. The $1-V$ characteristics point to the need for better Ohmic contacts and this is an area which is under current investigation. Some of series resistance in the GalnAsSb cievices could be due to a heterostructure barrier between GaInAsSb and $\mathrm{GaSb}^{(3)}$. The conduction and valence band discontinuities between $\mathrm{GaSb}$ and GalnAsSb are $0.24 \mathrm{eV}$ and $-0.1 \mathrm{eV}$ respectively. This is particularly troublesome and needs to be reduced by degenerately doping the junction or by bandgap grading.

Figure 7 shows the PV short circuit current density vs the blackbody temperature. It can be observed that for low temperature (1200K) TPV applications the narrow gap $(0.54 \mathrm{eV})$ cells are the answer because they offer more than three times the current density as compared to the $\mathrm{GaSb}(0.73 \mathrm{eV})$ cells.

Figure 8 plots the measured short circuit current densiry vs the open circuit voliage. Assuming the ideal diode relation

$$
I_{* c}=I_{0}\left[\exp \left\{q V_{\alpha} / n k T\right\}-1\right]
$$

where $I_{k}$ is the short circuit current, $I_{0}$ is the dark current, $V_{a c}$ is the open circuit voitage, $\boldsymbol{n}$ is the diode ideality factor, $\mathbf{k}$ is the Boltzmann constant and $\mathbf{T}$ is the temperature.

There are four potential dark current mechanisms: diffusion $(n=1)$, bulk recombination/regeneration $(n=2)$, surface recombination $(n=2)$ and band to band tunneling ( $n>2$ ). In Figure 8 we plotted the $I_{*}$ vs $V_{\infty}$ and fitted the ideal diode equation assuming a single dominant dark current mechanism. We found it useful to compare the data for our MBE grown GaInAsSb and GaSb diodes and JX Crystal LPE grown cells. At low current injection conditions MBE grown devices show a diode ideality factor of 2.43, indicating band to band tunneling, LPE devices showed a combination of diffusion and generation/recombination dark current. This difference could be due to a lower base doping for the LPE grown cells. Lower base doping leads to a lower $\mathrm{V}_{\infty}$. MBE cells show a higher $V_{w c}$ at a lower $l_{x c}$ (this is very desirable) as compared to $L P E$ cells. This data leads us to conclude that it is much more desirable to have an undoped intrinsic region between the $\mathrm{p}$ and $\mathrm{n}$ layers to reduce the itunneling component of the dark 
current. Some of the dark current could also be due to a lack of surface passivation. Use of an effective passivant or a high bandgap window layer will also reduce the dark current.

Figure 9 plots $V_{*}$ vs $T$ for MBE grown GaIn As\$b cells. This is done for various $I_{x}$ values. This data also helps determine the differences in the dominant dark current mechanisms. From low to high illumination levels the $V_{\text {or }}$ decreases linearly with temperature. The difference in the slope $\mathrm{dV} . / \mathrm{dT}$ between very low injection levels and higher injection levels indicate that at lower current levels the current is a combination of tunneling and some other mechanism, for higher injection levels once the tunneling barrier has been overcome the dark current mechanism is almost entirely due to tunneling ${ }^{(s)}$, this is indicated by a relatively small change in the $\mathrm{dV}_{\alpha} / \mathrm{dT}$ slope. It will be interesting to measure $\mathrm{dV} / \mathrm{dT}$ for even higher injection levels to see if other dark current mechanisms become dominant.

\section{Conclusions}

We have presented data on the current status of lattice matched GaInAsSb TPV devices and pointed out the areas in which improvements or device design changes are needed. Quaternary lattice matched TPV devices are very promising for thermal power conversion and offer superior performance due to potentially higher long term reliability and higher open circuit voltages and currents than lattice mismatched InGaAs/InP devices.

\section{References}

1) $1^{\text {a }}$ NREL Conference on the Thermophotovoltaic Generation of Electricity, Copper Mountain, CO, AIP Conference Proceedings 321 (1994).

2) $2^{\text {ad }}$ NREL Conference on the Thermophotovoltaic Generation of Electricity, Copper Mountain, CO, AIP Conference Proceedings 358 (1995)

3)M.P. Mikhailova and A.N. Titkov, Semicond. Sci. Tedhnol., 9, 1994, 1279-1295.

4)G.W. Charache, J.L. Egley, L.R. Danielson, D.M. Depoy, P.F. Baldasaro, B.C. Campbell, S. Hui, L.M. Fraas, and S.J. Wojtczuk 25th Photovoltaic Specialists Conference, Crystal City, VA, May 13-17, 1996. 


\section{TPV based upon Blackbody Emission}

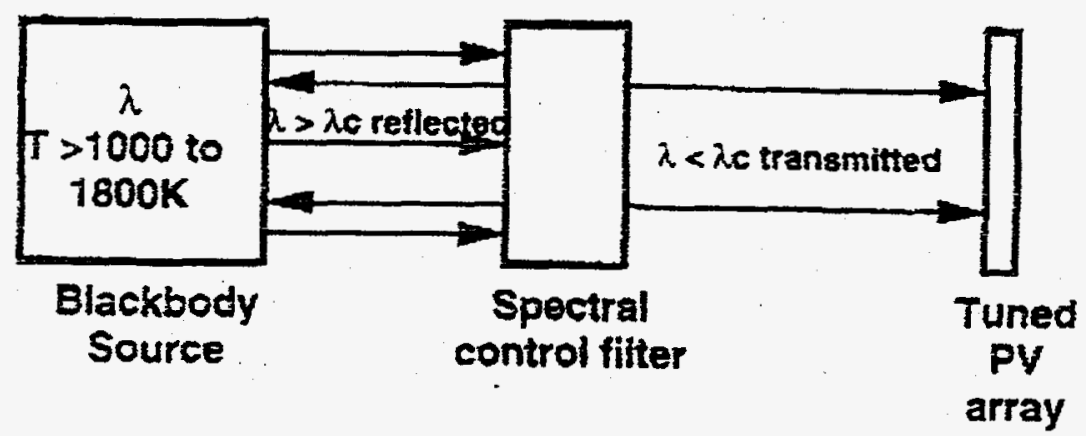


Emissive Power $\left(W / \mathrm{cm}^{\wedge} 2\right)$

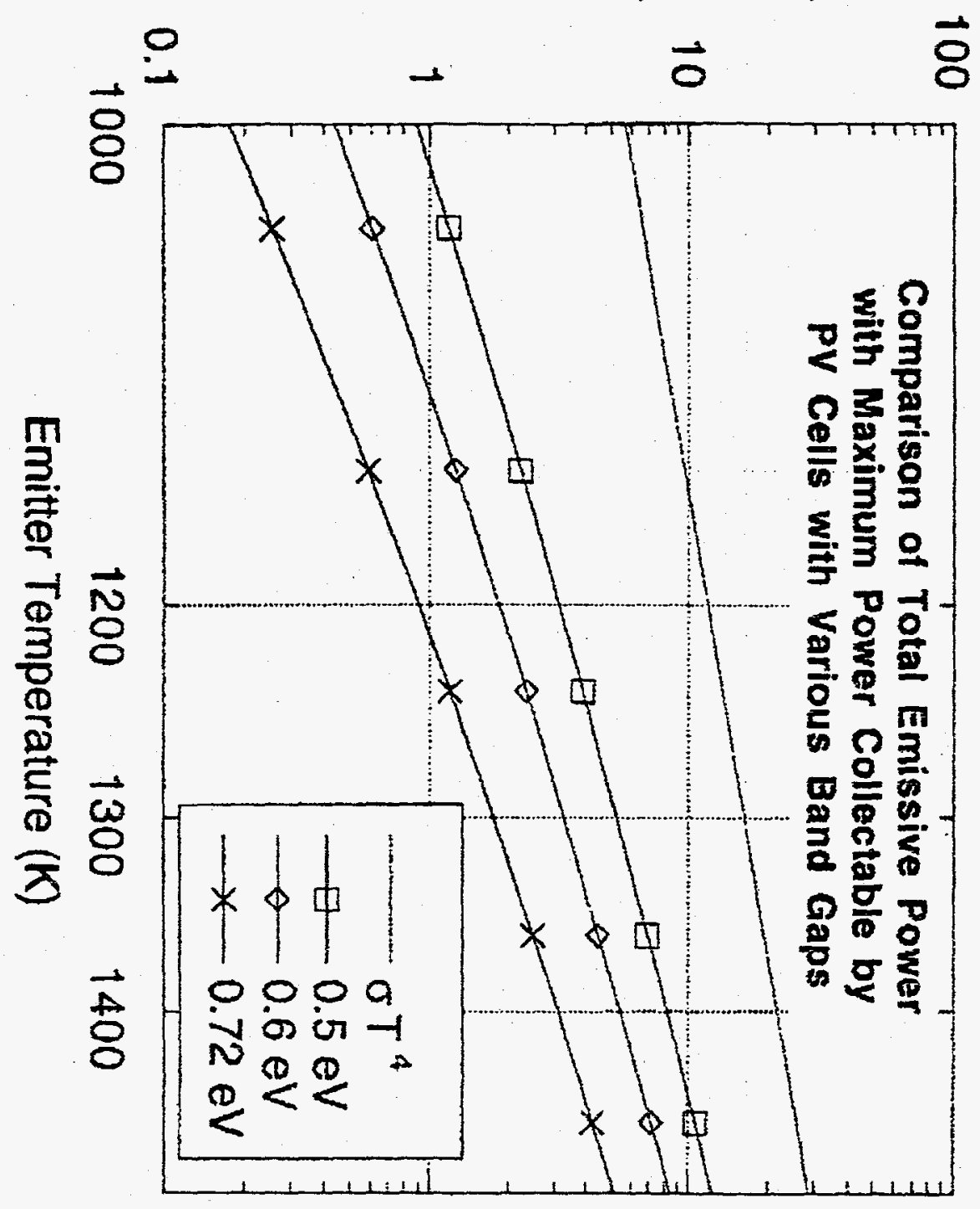



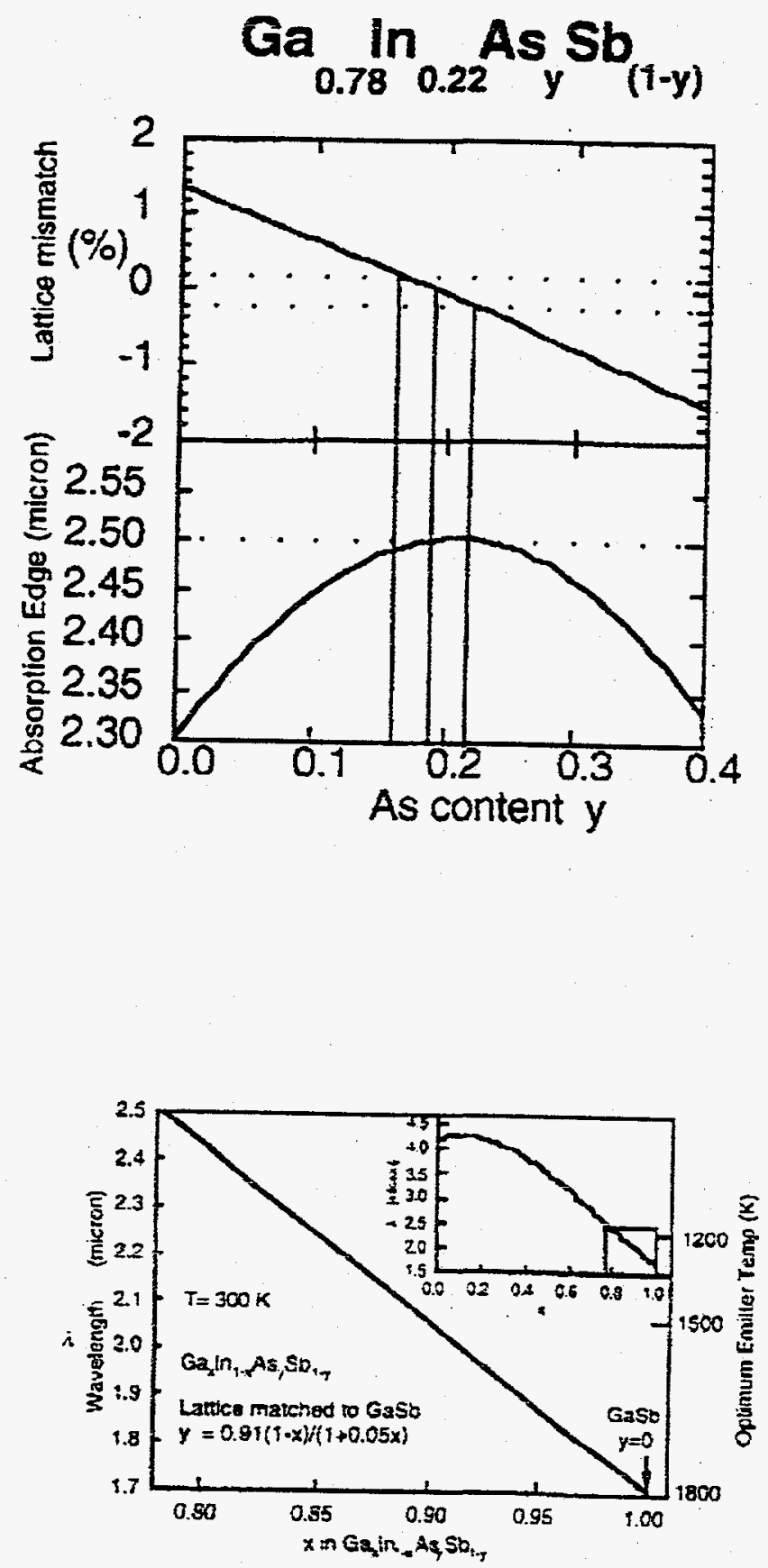
Incident Radiation

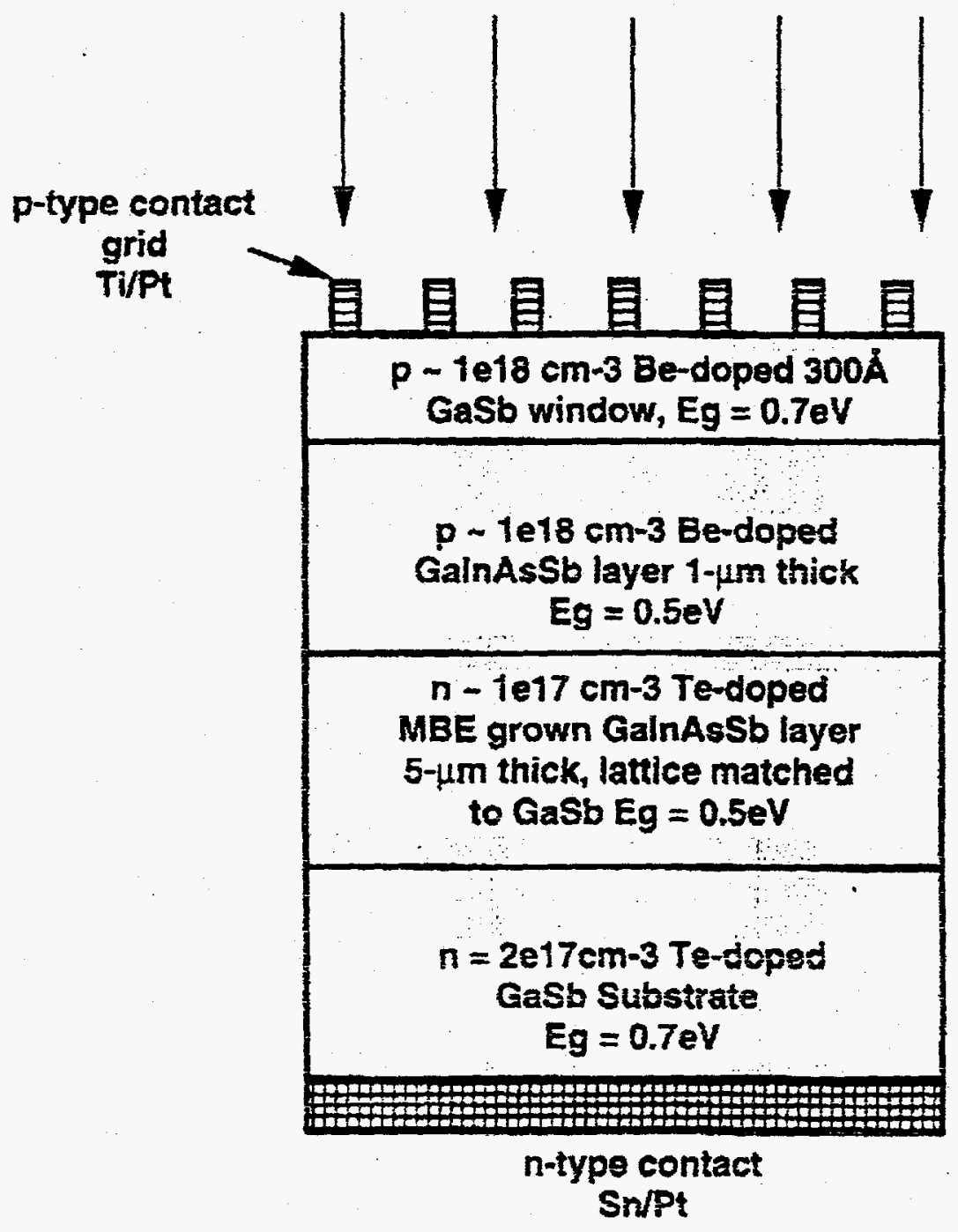




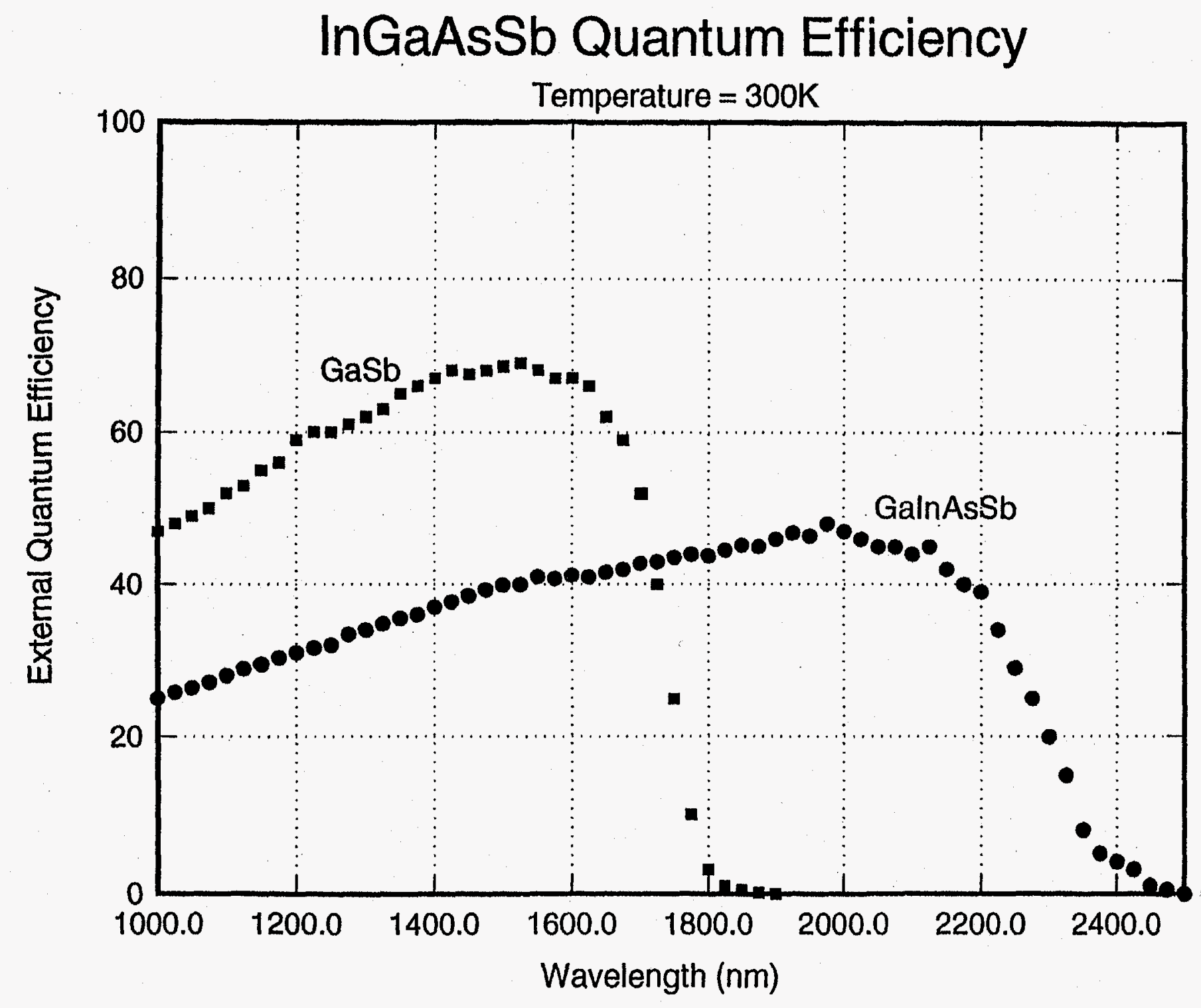



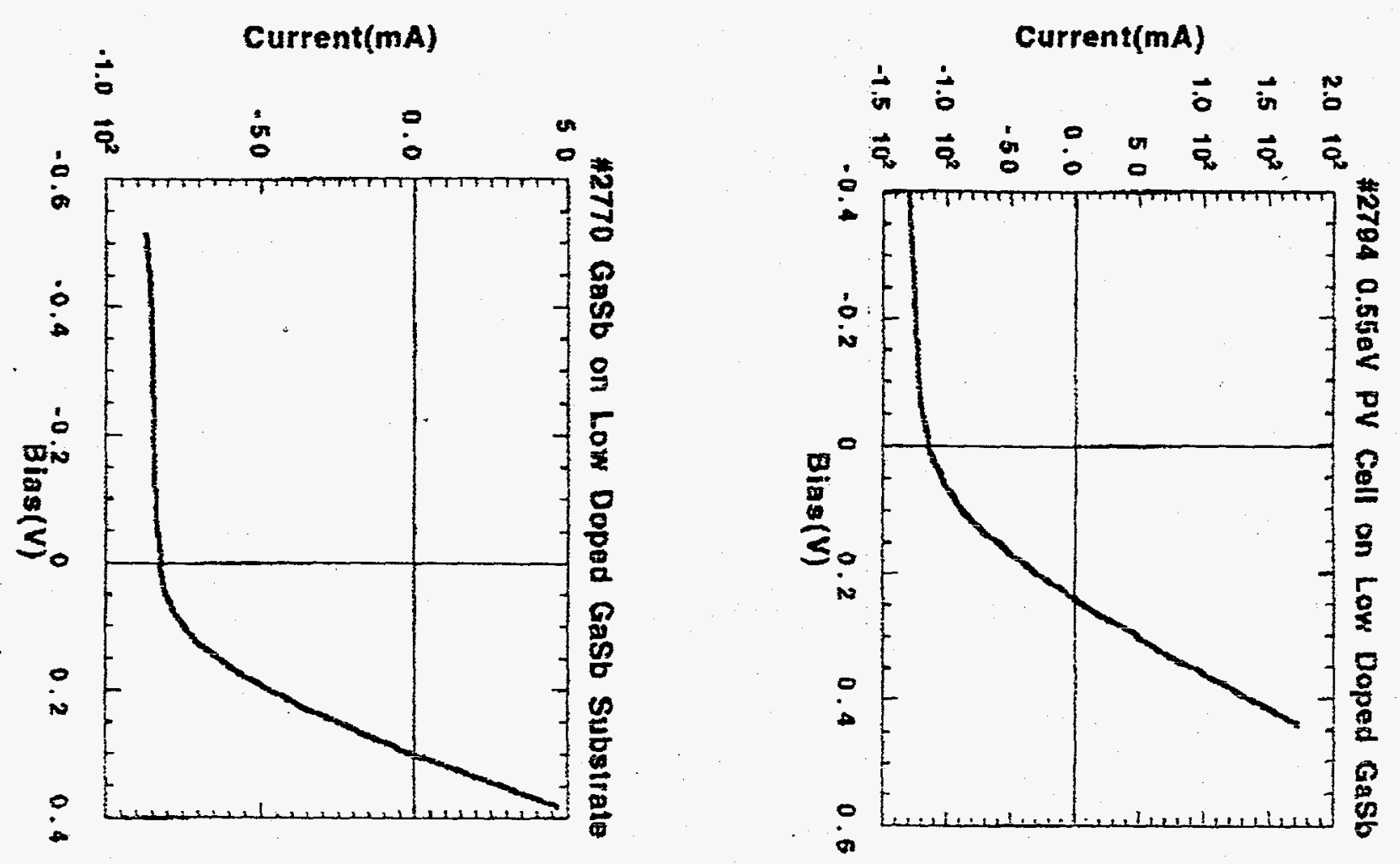
PV Cell Current Density vs Blackbody Temperature

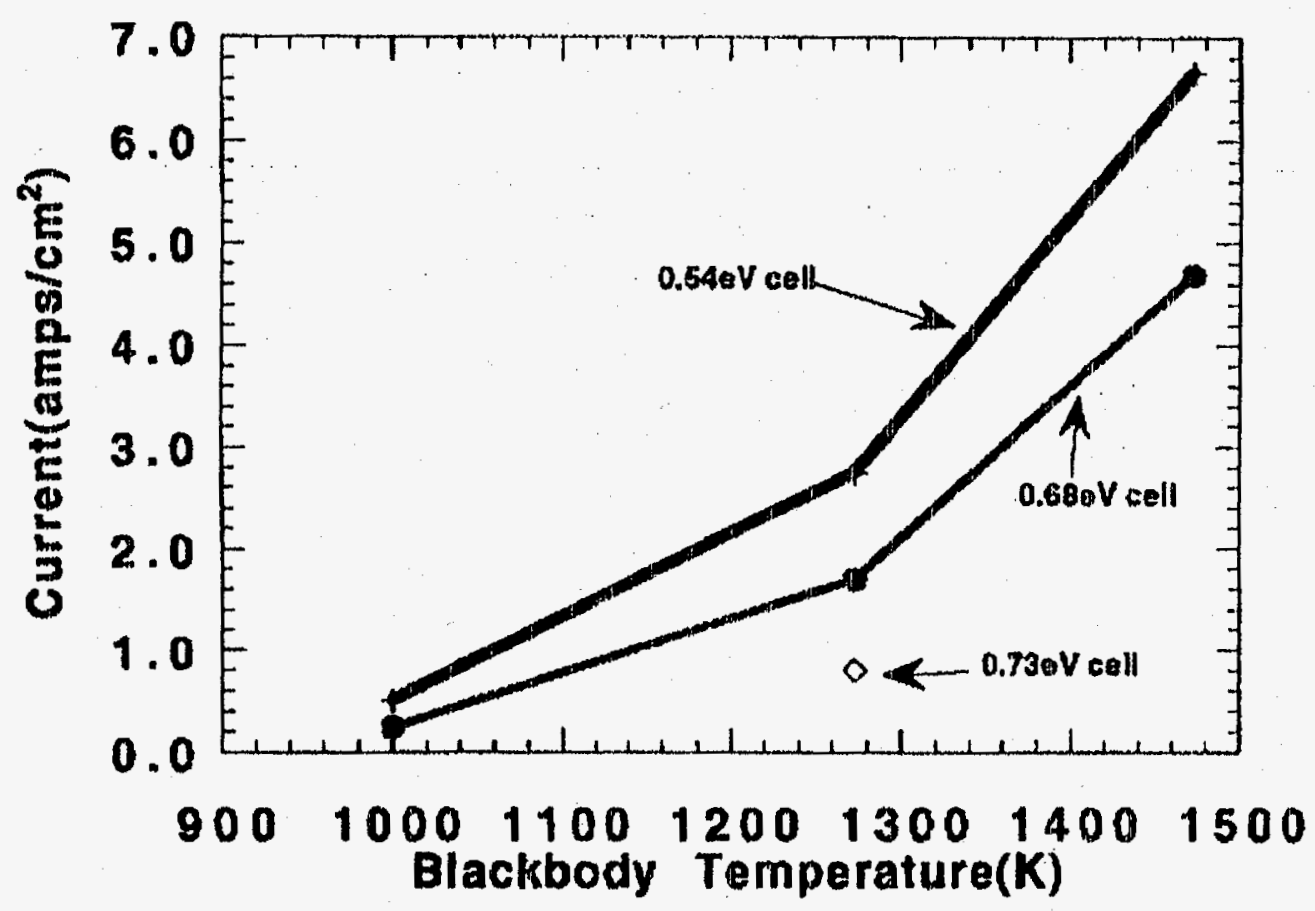


Short Circuit Current (mA)

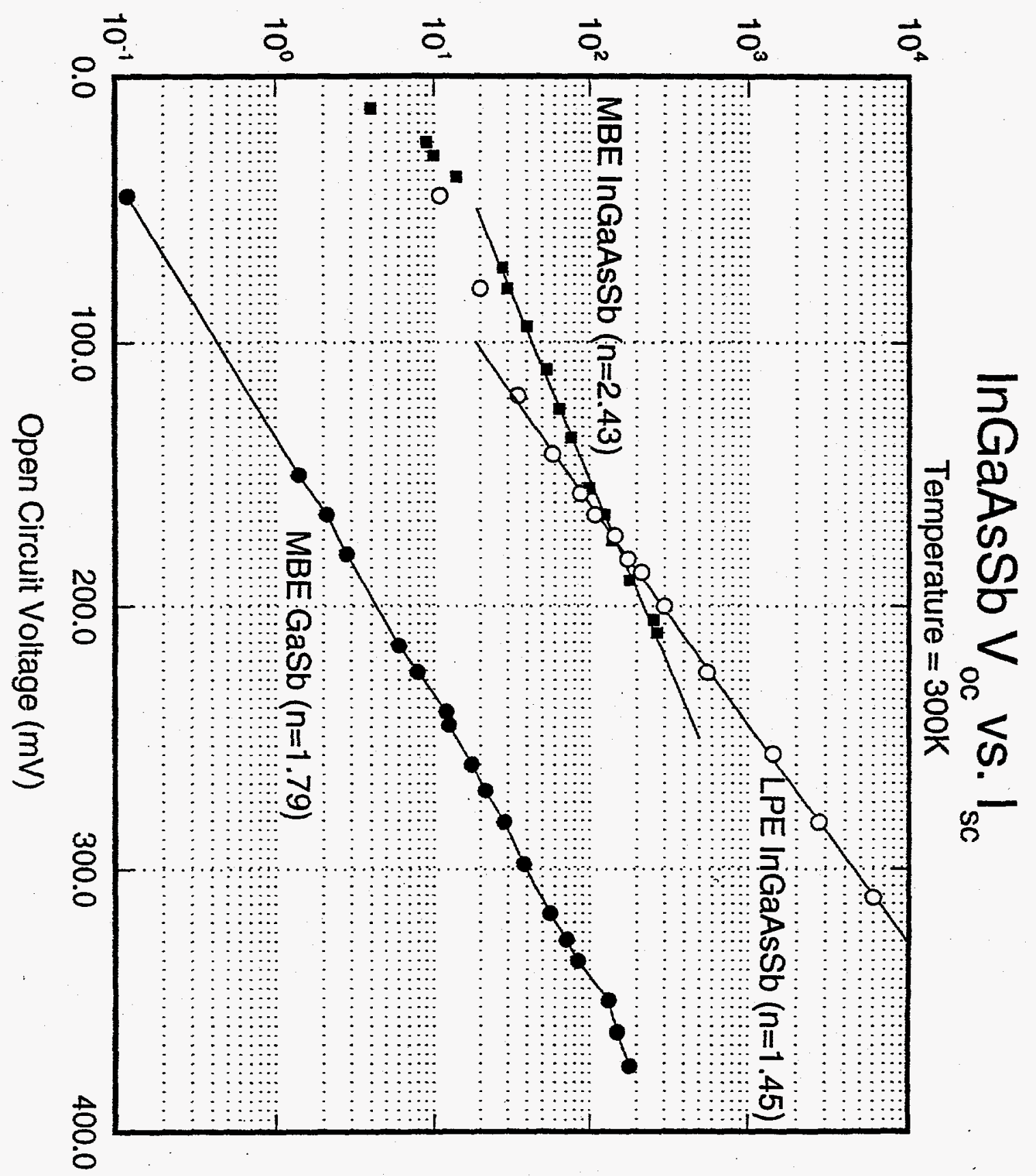




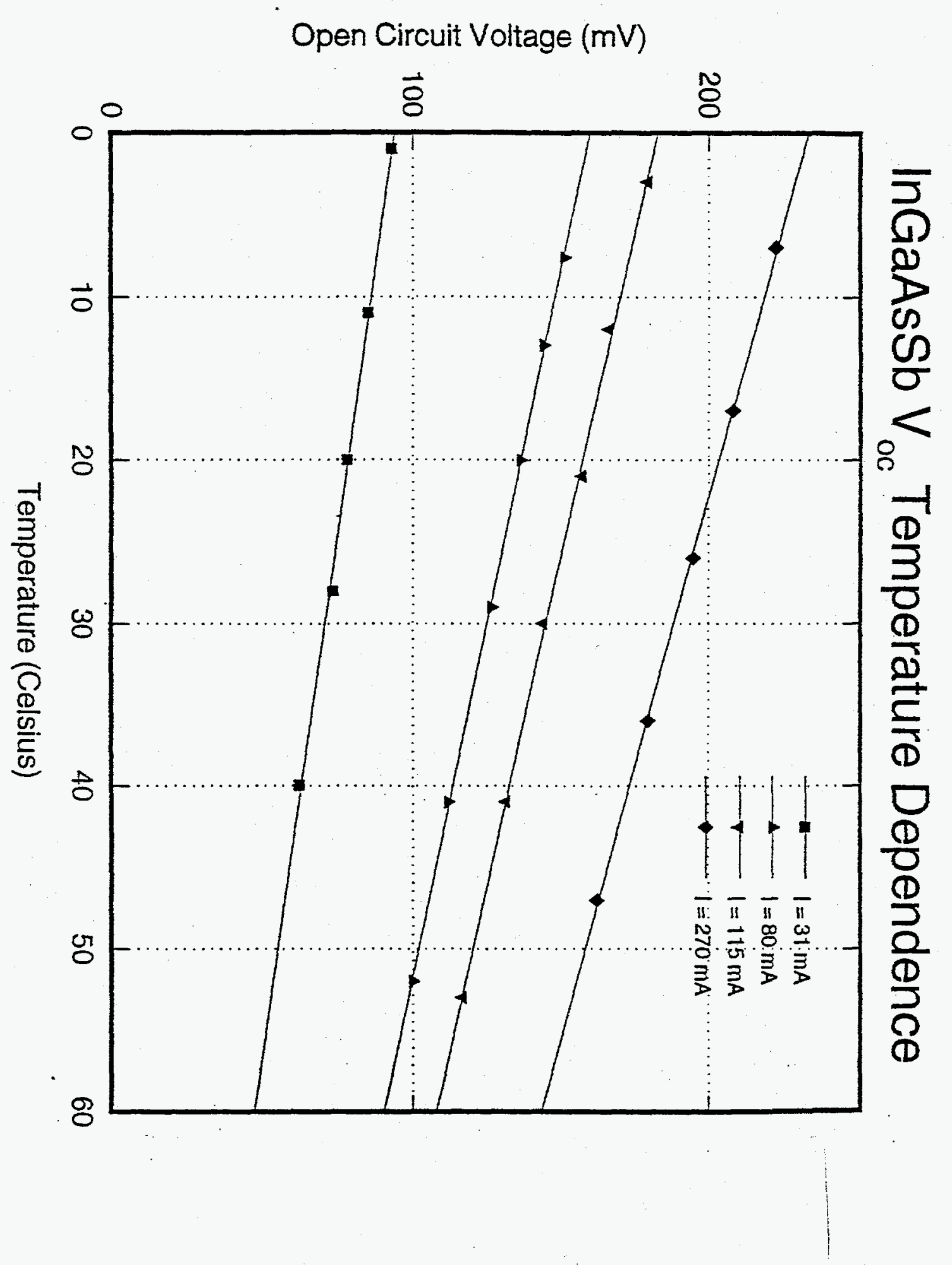

